\title{
Central sleep apnoea and periodic breathing in heart failure: prognostic significance and treatment options
}

\author{
Winfried Randerath ${ }^{1}$, Oana Claudia Deleanu², Sophia Schiza ${ }^{3}$ and Jean-Louis Pepin ${ }^{4}$ \\ Affiliations: ${ }^{1}$ Institute of Pneumology at the University of Cologne, Bethanien Hospital, Clinic for Pneumology \\ and Allergology, Centre of Sleep Medicine and Respiratory Care, Solingen, Germany. ${ }^{2}$ University of Medicine \\ and Pharmacy "Carol Davila", Bucharest, Romania. ${ }^{3}$ Sleep Disorders Centre, Medical School, University of \\ Crete, Heraklion, Greece. "Laboratoire du sommeil explorations fonctionnelle Respire, Centre Hospitalier \\ Universitaire Grenoble, Grenoble, France.
}

Correspondence: Winfried Randerath, Institute of Pneumology at the University of Cologne, Bethanien Hospital, Clinic for Pneumology and Allergology, Centre of Sleep Medicine and Respiratory Care, Aufderhöher Str. 169, 42699 Solingen, Germany. E-mail: randerathaklinik-bethanien.de

@ERSpublications

CSA in heart failure impairs outcome, but optimal treatment is intensively debated. Increasing evidence may guide to differentiation and individualised therapy of phenotypes according to differences in pathophysiology and treatment response. http://bit.ly/2kvTepX

Cite this article as: Randerath W, Deleanu OC, Schiza S, et al. Central sleep apnoea and periodic breathing in heart failure: prognostic significance and treatment options. Eur Respir Rev 2019; 28: 190084 [https://doi. org/10.1183/16000617.0084-2019].

ABSTRACT Central sleep apnoea (CSA) including periodic breathing is prevalent in more than onethird of patients with heart failure and is highly and independently associated with poor outcomes. Optimal treatment is still debated and well-conducted studies regarding efficacy and impact on outcomes of available treatment options are limited, particularly in cardiac failure with preserved ejection fraction. While continuous positive airway pressure and oxygen reduce breathing disturbances by $50 \%$, adaptive servoventilation (ASV) normalises breathing disturbances by to controlling the underlying mechanism of CSA. Results are contradictory regarding impact of ASV on hard outcomes. Cohorts and registry studies show survival improvement under ASV, while secondary analyses of the large SERVE-HF randomised trial showed an excess mortality in cardiac failure with reduced ejection fraction. The current priority is to understand which phenotypes of cardiac failure patients may benefit from treatment guiding individualised and personalised management.

\section{Introduction}

Breathing disturbances during sleep are characterised by three main pathophysiological components: obstruction of the upper airways, disturbances of respiratory drive and reduction of tidal volume. Although these components are most clearly represented in the protagonist diseases of obstructive sleep apnoea (OSA), central sleep apnoea (CSA) and hyperventilation, they can variably contribute to the specific clinical situation of individual patients. The analysis of the underlying pathophysiology may guide the therapeutic approach (figure 1). Diagnosis and optimal treatment of the central component is a major challenge due to the complexity of comorbid diseases and the prognostic impact of therapeutic options.

\section{CSA and periodic breathing: definition and characterisation}

Chronic heart failure (CHF) with reduced (HFrEF) and preserved (HFpEF) left ventricular ejection fraction (LVEF) is a major public health problem. Its prevalence is estimated to be $1-2 \%$ of the adult

Provenance: Commissioned article, peer reviewed

Received: 09 July 2019 | Accepted after revision: 30 Aug 2019

Copyright CERS 2019. This article is open access and distributed under the terms of the Creative Commons Attribution Non-Commercial Licence 4.0. 


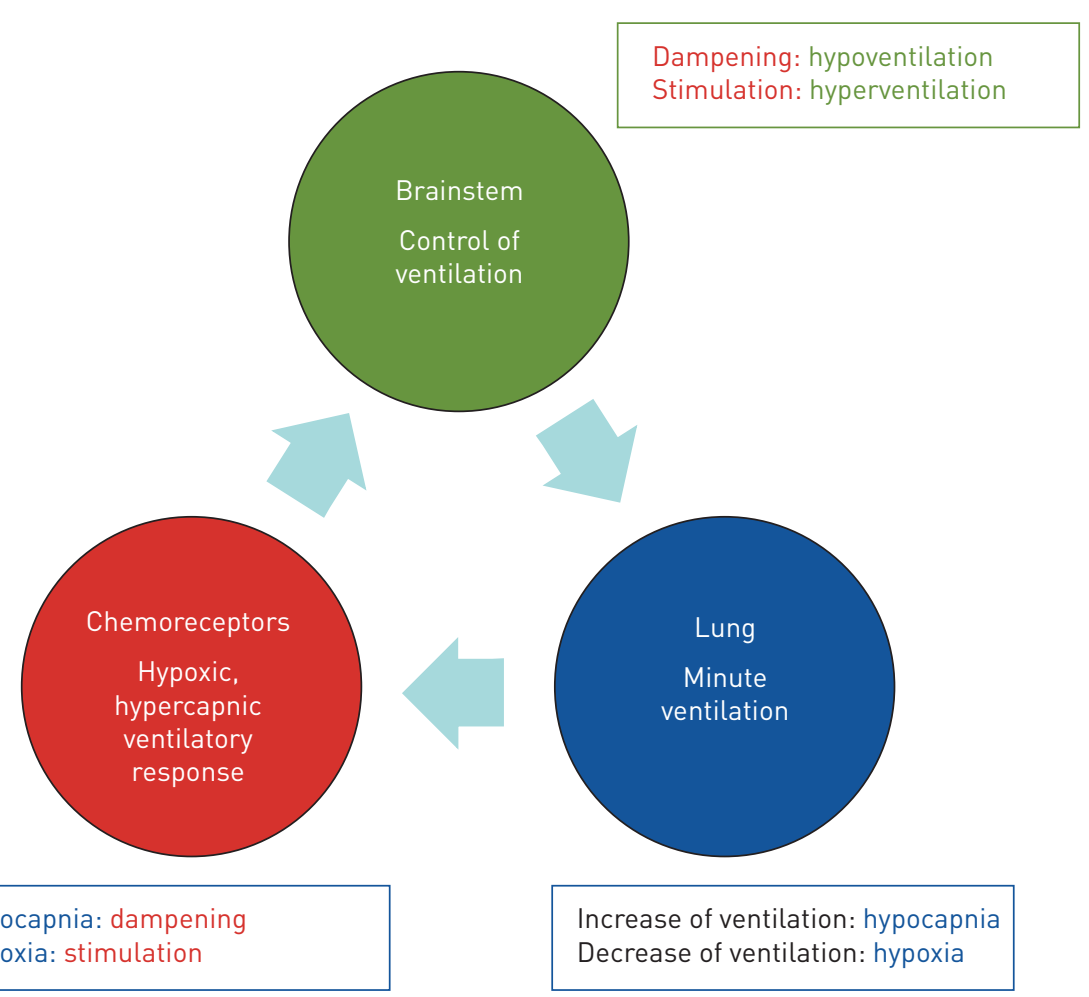

FIGURE 1 Illustration of the pathophysiological approach to treatment of sleep disordered breathing. Continuous positive airway pressure or expiratory positive airway pressure stabilise the obstructive component of the upper airways; variable pressure support or mandatory breaths counterbalance the overshoot and undershoot of ventilation due to brainstem disturbances; and reduction in tidal volume and minute ventilation require mechanical ventilation.

population in Western countries and increases with age [1]. Studies consistently demonstrated that $\geqslant 50 \%$ of CHF patients present with OSA and/or CSA, including its subtype labelled "periodic breathing". Data show a prevalence of $25-40 \%$ of periodic breathing in patients with HFrEF, increasing with male sex, the severity of left ventricular impairment and the presence of atrial fibrillation. The European Respiratory Society (ERS) task force on CSA recommends replacing the historical term "Cheyne-Stokes respiration" with "periodic breathing in heart failure" [2].

The SchlaHF registry including $>6500$ HFrEF patients reported a strong association between sleep disordered breathing (SDB), either OSA or CSA and body mass index. Age $>60$ years, atrial fibrillation, reduced LVEF and resting arterial carbon dioxide tension $\left(P_{\mathrm{aCO}_{2}}\right)<38 \mathrm{mmHg}$ during wakefulness were the most important risk factors for CSA/periodic breathing as compared to OSA [3, 4]. CSA has been demonstrated to be independently associated with worse outcomes in patients with HFrEF $[2,5,6]$ and has a higher socioeconomic burden. The higher mortality rate in CHF with periodic breathing may be related to intermittent hypoxia, arousals, increased sympathetic activity and mechanical impact on the heart of intrathoracic pressure swings. As improvement of prognosis in $\mathrm{CHF}$ was plateauing, there was a growing interest to include SDB as an actionable risk factor to be targeted by positive airway pressure therapies. A prerequisite was the understanding of the pathophysiology of CSA/periodic breathing to anticipate the effects of currently available therapies $[7,8]$.

\section{Pathophysiology}

Heart failure is differentiated based on the LVEF. Current guidelines separate $\operatorname{HFrEF}(<40 \%)$ from ejection fraction in the midrange $(40-49 \%)$ and HFpEF $(\geqslant 50 \%)$. Previous studies used a dichotomous separation of reduced and preserved ejection fraction. HFpEF patients generally do not present with dilated left ventricle, but increased wall sickness and increased left atrial size as a sign of increased filling pressure. Impaired left ventricular filling or suction capacity is a likely cause of heart failure in these patients (diastolic heart failure). HFrEF presents with dilation of the left ventricle. All phenotypes are characterised by symptoms of breathlessness, peripheral oedema and fatigue due to pulmonary congestion and reduced output. There is a bidirectional relationship between heart failure and SDB. SDB may exaggerate myocardial remodelling and function due to repetitive hypoxia, arousals and sympathetic activation [1]. 
Dysregulation of control of breathing plays the major role in the pathophysiology of CSA, with well-established differences compared to healthy individuals and heart failure patients free of SDB (figure 2). The term "loop gain" is used to describe the adaptation of ventilation to any disturbance reflecting the reactivity of the ventilatory system including the lungs (plant gain), the peripheral chemoreceptors (feedback gain) and the central chemoreceptors at the brainstem (controller gain). A high loop gain producing overshoot and undershoot of ventilation in responses to disturbances indicates instability of the system associated with overresponsiveness of the chemoreceptors and increased brainstem activity. While a high loop gain is typical in periodic breathing, a lower loop gain represents a dampening of the ventilatory system in hypoventilation disorders. A typical polysomnographic pattern of a high loop gain is represented by long-lasting apnoeic episodes followed by abrupt and sharp hyperventilation. SDB in the context of a low loop gain depicts prominent hypopnoeas or short apnoeas with limited hyperventilation ending the events [7].

A majority of CSA patients presents with chronic hyperventilation characterised by normocapnia or hypocapnia (increased plant gain). Pulmonary congestion in CHF activates vagal J-receptors in lung parenchyma, which in turn stimulate brainstem activity and generate hyperventilation [7]. The hypercapnic ventilatory responses, i.e. changes in minute ventilation to variations of carbon dioxide $\left(\mathrm{CO}_{2}\right)$ are elevated (increased feedback gain). Such an excessive chemosensitivity triggers ventilation instability with exaggerated hyperventilation in reaction to mild increases in $\mathrm{CO}_{2}$ and hypoventilation or apnoeas in response to hypercapnia. These mechanisms are summarised by the typical polysomnographic pattern of overshoot and undershoot of ventilation, the crescendo-decrescendo variations in tidal volume and respiratory effort. The instability and increased reactivity of the control of ventilation is perpetuating a vicious circle: hyperventilation (overshoot) reduces the actual $\mathrm{CO}_{2}$ tension below the apnoeic threshold, which dampens the neural drive and induces central apnoeas. Central apnoeas are associated with a rise in $P_{\mathrm{aCO}_{2}}$ and a decrease in arterial oxygen tension, stimulating ventilation and creating the next overshoot. Experimental data from animal studies and in clinical setting demonstrated that a prolonged circulation time between the alveoli and the brainstem amplifies this vicious circle. However, there is insufficient evidence to translate these data to humans [9].

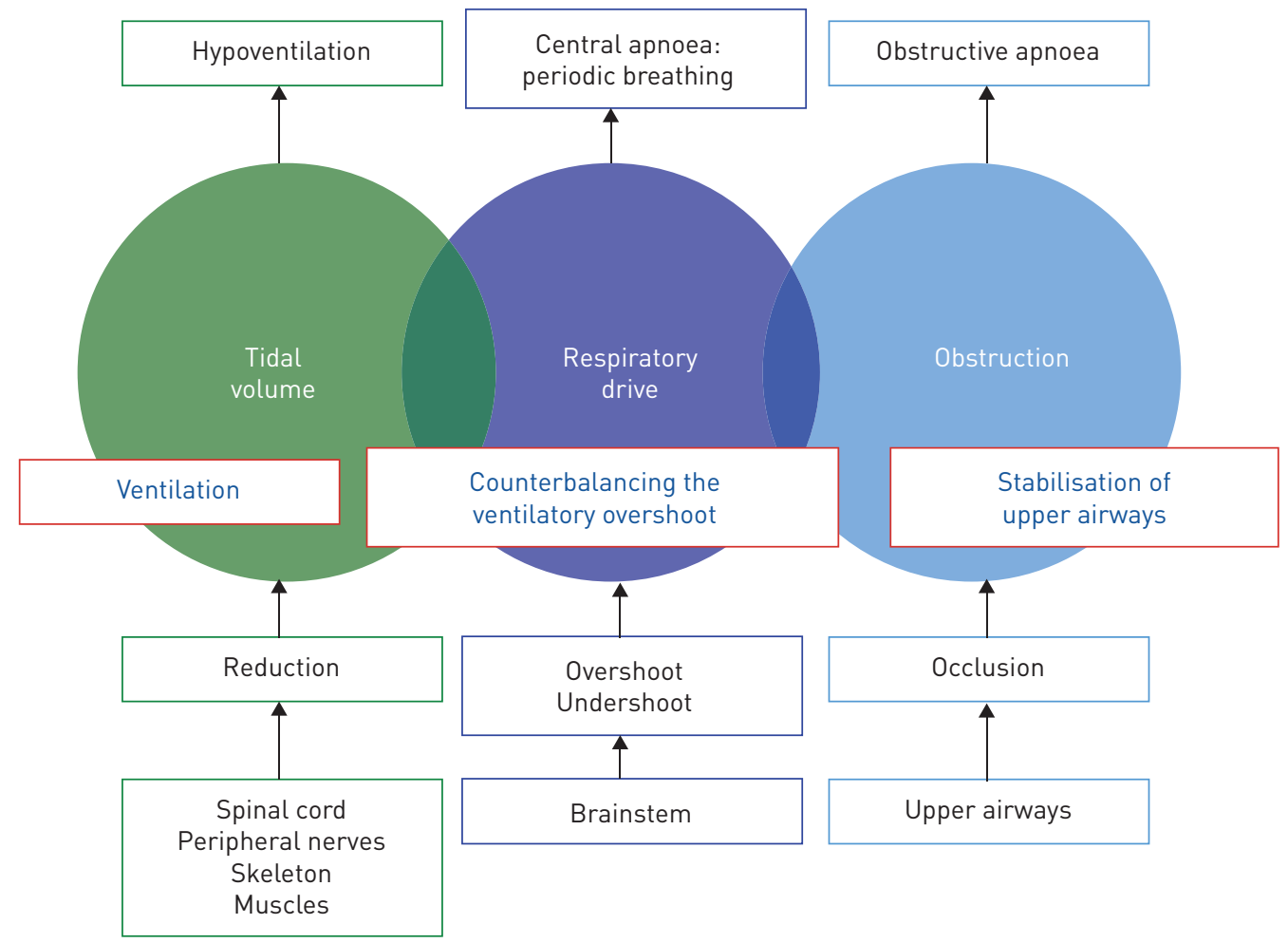

FIGURE 2 The respiratory system is composed of three components, which have been described as a loop gain. Imbalance of the loop gain may lead to a vicious circle of overshoot and undershoot of the ventilation: any inadequate increase of the ventilation induces hypocapnia; hypocapnia dampens the carbon dioxide-sensitive chemoreceptors, leading to a dampening of the inspiratory impulses of the brain stem. As a consequence, minute ventilation (generated from the plant gain) is reduced, leading to hypoxia; hypoxia stimulates the chemoreceptors and consecutively respiratory drive. 
At the end stages of the disease, periodic breathing is not limited to sleep, but can also appear at rest or during exercise in advanced CHF [10-15]. Recently, it has been discussed that periodic breathing (although a marker of severity and poor prognosis) may represent a compensatory mechanism to limit the deleterious effects of heart failure. Periodic breathing-related large intrathoracic pressure swings, elevations of end-expiratory lung volume (EELV) and increased vagal tone from intrinsic positive end-expiratory airway pressure, improved ventilation/perfusion matching and reduced work of breathing might improve heart mechanics and stabilise left ventricular function [16]. However, this hypothesis is mainly supported by mathematical models and experimental studies in small sample size studies in healthy humans, making the translation to CHF patients difficult [17-21]. Moreover, it can be argued that this hypothesis rather supports the application of positive airway pressure therapies expected to have similar effects on lung volumes, cardiac mechanics and intrathoracic pressures.

\section{Challenges in managing CSA/periodic breathing in CHF with reduced ejection fraction}

The potential contribution of CSA/periodic breathing on decline in heart function and outcomes motivated clinicians and researchers to delineate optimal treatment strategies. Therapeutic goals include improvement in cardiac function, reduction of hospitalisations, morbidity and mortality and, if these are not possible, enhancement of quality of life (QoL) [22].

The ERS task force on CSA discussed the various treatment options [2] (figure 3). The first step of current practice is to optimise medical therapy of cardiac failure with diuretics to reduce pulmonary congestions and cardiac filling pressures, with angiotensin-converting enzyme inhibitors to reduce ventricular afterload [23] and with $\beta$-blockers to diminish excessive sympathetic activation [24, 25]. Physical activity, compression stockings, salt restriction and dialysis can also reduce fluid overload and accumulation in the

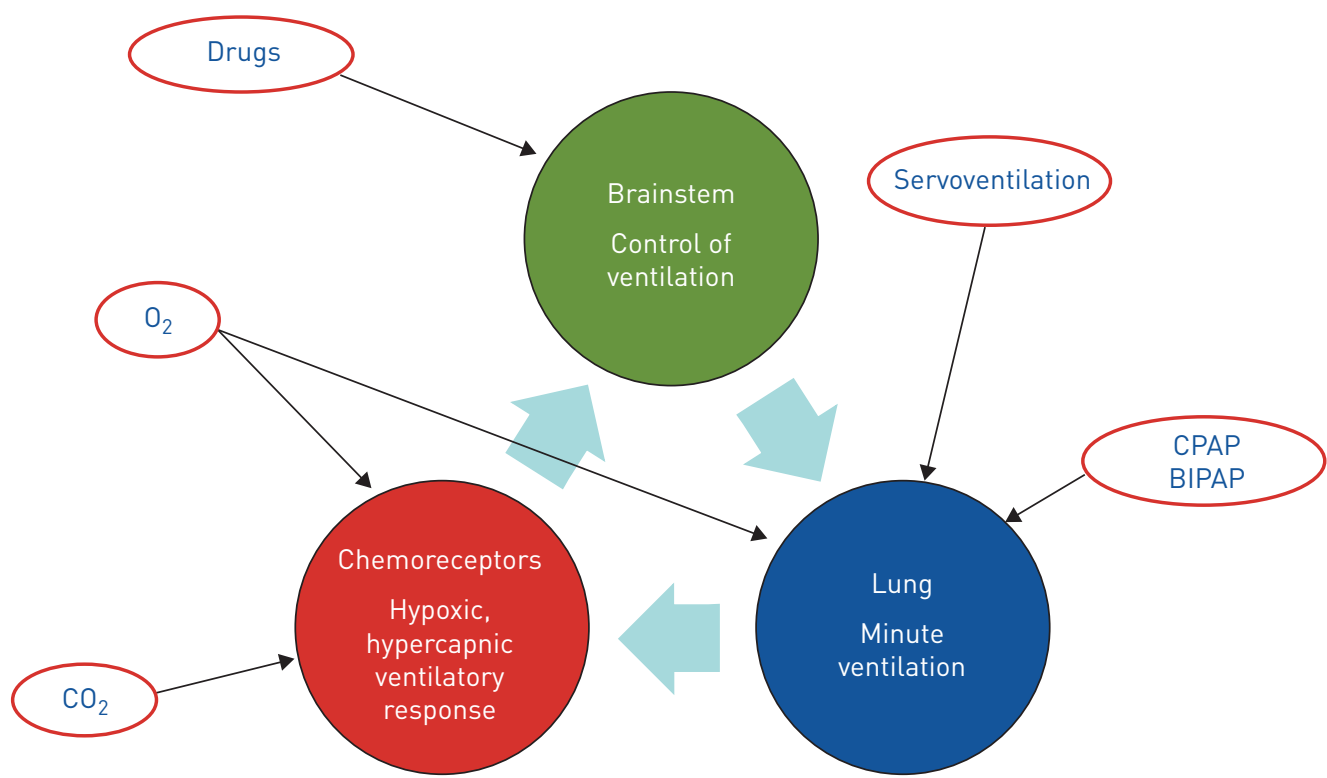

FIGURE 3 The figure shows the approaches of various treatment options on the loop gain. Oxygen $\left(\mathrm{O}_{2}\right)$ supply increases the alveolar $\mathrm{O}_{2}$ concentration and avoids hypoxic stimulation of the chemoreceptors. In addition, it may influence myocardial function. Carbon dioxide $\left(\mathrm{CO}_{2}\right)$ plays a major role in the pathophysiology of periodic breathing. The application of $\mathrm{CO}_{2}$ by rebreathing or external supply elevates the arterial $\mathrm{CO}_{2}$ tension above the apnoea threshold and impedes central apnoeas. Drugs may influence respiratory drive in the brainstem. Some pharmaceutical influences on arousability, sleep stages and sleep efficiency can stabilise respiration or shift sleep stages from non-rapid eye movement (REM) stages I and II to slow-wave or REM sleep. CPAP: continuous positive airway pressure; BIPAP: bilevel positive airway pressure. 
lower body compartment during the day and diminish nocturnal fluid shift to lungs and upper airways [26]. In addition, optimal cardiac treatment includes interventional or surgical therapies on cardiac vessels or valves. Resynchronisation therapy has been shown to decrease breathing disturbances [27], improve cardiac function, QoL and mortality in advanced heart failure.

In randomised controlled trials (RCTs) with small sample sizes, nocturnal oxygen therapy ameliorates CSA in heart failure patients, essentially by reducing hypoxic ventilatory drive and sympathetic activation. The apnoea-hypopnoea index (AHI) is reduced by $50 \%$ without significant change in the obstructive component [28]. Oxygen may improve physical activity and QoL [29]. Evidence is limited and large RCTs need to be conducted in this field.

Studies investigated the effect of added dead space and external $\mathrm{CO}_{2}$ application for increasing $P_{\mathrm{aCO}}$ above the apnoeic threshold and thus stabilising ventilation. Although this approach is highly effective in experimental settings, the treatment cannot currently be recommended due to a lack of safety and long-term data [2, 30-32].

Theophylline has shown modest efficacy on improvement of periodic breathing, AHI and intermittent hypoxia. However, beneficial effects on cardiac function or sleep architecture were limited [33].

Most recently, unilateral phrenic nerve stimulation has been introduced in the treatment of CSA in CHF. Comparable to oxygen and continuous positive airway pressure (CPAP), it may reduce central AHI by $50 \%$, but long-term and large-scale data are missing. Data regarding hard outcomes are lacking. Therefore, the treatment should be used very cautiously in selected populations participating in controlled trials [34, 35].

CPAP primarily re-opens and stabilises the upper airway, but may also influence left ventricular afterload and filling of the right heart, improve ventilation/perfusion mismatch and slightly increase $P_{\mathrm{aCO}_{2}}$. Cohort and RCT studies have suggested that CPAP improves oxygenation and LVEF [36]. CPAP reduces central breathing disturbances by a mean of 50\%. However, the CANPAP trial failed to show a survival benefit in patients with CSA and CHF with reduced LVEF [36]. Bilevel positive airway pressure (BPAP) with back-up mandatory breaths may abolish both obstructive and central SDB. However, data on the clinical use in patients with CHF and CSA/periodic breathing are scarce. DeLLwEg et al. [37] showed that short-term beneficial effects of BPAP were lost over time. In addition, BPAP may even aggravate central events by inducing hypocapnia and facilitating glottis closures. Therefore, the ERS task force on CSA did not support the use of BPAP in CHF with CSA/periodic breathing outside clinical trials [2].

Adaptive servoventilation (ASV) adjusts the breath-after-breath level of inspiratory pressure support in order to counterbalance the overshoot and undershoot of ventilation. ASV devices increase pressure support during apnoeic/hypopnoeic periods and reduce it during hyperventilation. In addition, ASV devices provide fixed or variable expiratory pressure to suppress obstructive events and apply mandatory breaths to avoid central apnoeas [38]. Therefore, ASV normalises obstructive and central SDB and is superior to CPAP, oxygen or other therapeutic approaches [15, 37, 39-44] for suppressing sleep disturbances. However, the SERVE-HF trial, which compared optimum medical treatment for heart failure alone (control group) or in combination with adaptive servoventilation in severe CHF with reduced LVEF $(<45 \%)$ and predominant CSA failed to show a prognostic benefit of ASV [45]. The primary end-point was neutral and secondary end-points analysis showed that all-cause and cardiovascular mortality were both increased [45]. To date, this is by far the largest RCT in the field and the results have led to contraindication of ASV in cardiac failure with reduced ejection fraction below $45 \%$ according to the SERVE-HF inclusion criteria.

However, the study results have been challenged owing to a high percentage (23\%) of the study population switching from control to ASV or vice versa, low ASV adherence (40\% of patients used the ASV device $<3 \mathrm{~h}$ per day, $26.7 \% 0 \mathrm{~h}$ per day) and unbalanced use of antiarrhythmic drugs between the two arms $[45,46]$. Post hoc analyses showed that ASV negative impact was mainly restricted to patients with the lowest LVEF $(<30 \%)$ and those with the highest proportion of periodic breathing [22, 47]. Therefore, the contraindications of ASV should not been extended to the CHF population with preserved ejection fraction and/or to HFrEF $>45 \%$.

The unexpected results of SERVE-HF raised several questions on possible explanations for the higher mortality burden. JAVAHERI et al. [48] hypothesised that cardiac instability rather than effects of the treatment may be responsible for the mortality in SERVE-HF.

In fact, patients did not die from decompensation or progressive deterioration in heart failure, but from sudden cardiac death. The following hypothesis has been proposed: 1) the highest risk of sudden cardiac death occurred in the most severe patients (very low LVEF, <30\%); 2) patients with poor outcomes were significantly more often treated with drugs which themselves induce cardiac instability (antiarrhythmics); 
3) JAVAHERI et al. [48] discussed whether, against the background of these unfavourable preconditions, unnecessary pressure support and hyperventilation might have facilitated malignant arrhythmias.

Physiological studies suggest that algorithm might play a role. However, we do not have data to demonstrate that these acute physiological measurements translate into significant impact on outcomes [49].

Although more recent studies (non-RCT) showed beneficial effects of ASV (table 1), the results of another large, multicentre, multinational trial (ADVENT-HF) are required to truly evaluate the efficacy, benefits and potential harms of ASV treatment in cardiac failure with reduced ejection fraction. Similar to SERVE-HF, ADVENT-HF includes patients with CHF with an LVEF <45\% under optimal medical therapy and with AHI $\geqslant 15$ events. ${ }^{-1}$. However, ADVENT-HF includes OSA patients and uses an ASV device, which allows reduction of pressure support to zero. Most recently, preliminary results proved better treatment adherence in ADVENT-HF compared to SERVE-HF [57].

\section{Is periodic breathing in CHF a unique entity?}

The heterogeneous and contradictory results on ASV ask for new concepts in our understanding of CSA. The goal of tailoring of CSA/periodic breathing therapies in order to maximise the treatment response requires more accurate patient's phenomapping than reporting solely on AHI. CHF patients are particularly heterogeneous in terms of clinical, imaging and biological characteristics, but also concerning physiopathological traits underlying CSA/periodic breathing patterns during sleep. The overarching goal is to combine both standard clinical/biological parameters of $\mathrm{CHF}$ and the following complex polysomnographic patterns informing on mechanistic traits of SDB [58]. Recent studies indicate parameters possibly explaining heterogeneous response to treatment and survival, as follows.

\section{Loop gain}

A post hoc analysis of the CANPAP study demonstrated significant survival benefit in those patients with significant improvement of central breathing disturbances under CPAP (responders) [59]. On the one hand, it can be discussed that optimal suppression of breathing disturbances improves survival. On the other hand, treatment response and survival benefit can be a characteristic of a specific phenotype. SANDS et al. [18] analysed loop gain in CHF patients according to their CPAP response. They found that low loop gain was associated with better CPAP response, while high loop gain (high instability of the respiration) was associated with poor CPAP efficacy.

\section{Exercise oscillatory ventilation}

KAZIMIERCZAK et al. [15] assessed exercise oscillatory ventilation, a common pattern in heart failure patients characterised by significant variations in minute ventilation during increased workload. They studied 39 CHF patients with $\mathrm{LVEF}<45 \%$ and found that exercise oscillatory ventilation was associated with the severity of heart failure and can be reversed with ASV therapy.

\section{Hypoxic burden}

WatANABE et al. [60] measured the hypoxic burden as defined by the time with oxygen desaturation $>4 \%$. Survival was significantly impaired in those patients with higher total time with oxygen desaturation $<4 \%$, but did not depend on the number of oxygen desaturations.

\section{Pattern of oxygen desaturation}

Granitza et al. [61] used mathematical methods to analyse the pattern of oxygen desaturation. They differentiated a dynamic and a static desaturation pattern. Oxygen desaturation $>8 \%$ was a strong predictor of fatal events. CHF patients who died had shown a bimodal distribution of oxygen desaturation with two peaks, one with a mean desaturation of $2 \%$ and one with a mean desaturation of $8 \%$. In contrast, survivors showed a Gauss-like distribution of the oxygen desaturation with a maximum at $4 \%$.

\section{EELV}

Based on previous findings of BRACK et al. [17], PERGER et al. [62] focused on the EELV in periodic breathing. They found two patterns, one with EELV higher than functional residual capacity (positive pattern), and one with negative EELV. The negative pattern was associated with longer hypopnoea and cycle time, higher N-terminal pro-brain natriuretic peptide and worse New York Heart Association classes.

\section{Hypoxic and hypercapnic ventilator responses}

GIANNONi et al. [63] measured the hypoxic and hypercapnic ventilatory responses in patients with HFrEF with a LVEF of $31 \pm 7 \%$. During the mean follow-up period of 29 months, survival was best in patients with normal chemosensitivity, while it was reduced in patients with either increased hypoxic or 
TABLE 1 Adaptive servoventilation (ASV) studies with mortality as primary outcome after SERVE-HF

\begin{tabular}{|c|c|c|c|c|c|c|}
\hline $\begin{array}{l}\text { Study/authors, } \\
\text { year } \\
\text { [reference] }\end{array}$ & Design & Population & Intervention & Primary outcome & $\begin{array}{l}\text { Median or } \\
\text { average } \\
\text { follow-up }\end{array}$ & Results \\
\hline $\begin{array}{l}\text { FACE study, } \\
2016[50]\end{array}$ & $\begin{array}{c}\text { Prospective } \\
\text { multicentre } \\
\text { observational cohort } \\
\text { France } \\
\text { Up to January 31, } \\
2013\end{array}$ & $\begin{array}{c}\text { CHF with reduced LVEF } \\
\text { (HFrEF }<40 \%) \text {, mid-range } \\
\text { (HFmrEF 40-49\%), } \\
\text { preserved (HFpEF >50\%) }\end{array}$ & $\begin{array}{l}361 \text { CHF patients with CSA } \\
\text { eligible for ASV therapy } \\
\text { (n=258) versus controls } \\
\text { (n=133) refused/not } \\
\text { compliant with ASV (<3 h per } \\
\text { night) } \\
\text { (ResMed, AutoSet CS) } 66 \% \\
\text { compliant to ASV therapy }\end{array}$ & $\begin{array}{c}\text { All-cause death, hospitalisation for } \\
\text { worsening heart failure, heart } \\
\text { transplant or ventricular assist } \\
\text { device }\end{array}$ & 21.6 months & $\begin{array}{l}\text { ASV improved prognosis in } \\
\text { HFmEF in non-ischaemic } \\
\text { heart failure; trend to } \\
\text { increase in event rate in } \\
\text { HFmrEF in ischaemic } \\
\text { heart disease; improved } \\
\text { prognosis in HFpEF CHF } \\
\text { with severe desaturations }\end{array}$ \\
\hline $\begin{array}{l}\text { CAT-HF study, } \\
2017[51]\end{array}$ & $\begin{array}{c}\text { Prospective, } \\
\text { randomised, } \\
\text { controlled, } \\
\text { multicentre clinical } \\
\text { trial } \\
\text { United States and } \\
\text { Germany } \\
2013-2015\end{array}$ & $\begin{array}{l}\text { Hospitalised heart failure } \\
\text { (HFrEF }>45 \% \text { or HFpEF } \\
\geqslant 45 \% \text { ) and SDB (OSA or } \\
\text { CSA) with AHI } \\
\geqslant 15 \text { events } h^{-1} \text { via } \\
\text { polygraphy }\end{array}$ & $\begin{array}{l}126 \text { out of } 215 \text { patients } \\
\text { assigned on ASV plus } \\
\text { optimised medical therapy } \\
\text { ( } \mathrm{n}=65 \text { ) versus optimised } \\
\text { medical therapy alone } \\
\text { (control) (n=61) }\end{array}$ & $\begin{array}{l}\text { Composite global rank score (death, } \\
\text { CV hospitalisations, and percentage } \\
\text { changes in 6-min walk distance) } \\
\text { Secondary end-points: sleep apnoea } \\
\text { parameters, functional capacity, } \\
\text { cardiovascular and all-cause death, } \\
\text { days alive and out of the hospital, } \\
\text { biomarkers, QoL, sleep parameters, } \\
\text { imaging parameters and NYHA } \\
\text { functional class }\end{array}$ & 6 months & $\begin{array}{c}\text { Neutral } \\
\text { No improvement in } \\
\text { 6-month cardiovascular } \\
\text { outcomes; however, a } \\
\text { positive effect of ASV in } \\
\text { patients with HFpEF } \\
\text { Study was stopped after } \\
\text { publication of SERVE-HF }\end{array}$ \\
\hline $\begin{array}{l}\text { IMAMURA et al., } \\
2016 \text { [52] }\end{array}$ & $\begin{array}{l}\text { Case-control study } \\
\text { Tokyo, Japan } \\
\text { 2008-2014 }\end{array}$ & $\begin{array}{c}\text { Heart failure NYHA III or IV } \\
\text { (71\% NYHA IV, LVEF } 33 \\
\pm 17 \% \text { ) with ASV irrespective } \\
\text { of SDB }\end{array}$ & $\begin{array}{c}85 \text { patients receiving ASV } \\
1 \text { month versus } \\
\text { guideline-directed medical } \\
\text { therapies } \\
\text { (AutoSet-CS; ResMed, } \\
\text { Sydney, Australia) with full } \\
\text { face mask (ResMed) }\end{array}$ & $\begin{array}{c}\text { All-cause mortality and cardiac } \\
\text { deaths }\end{array}$ & $\begin{array}{l}\text { 2-year } \\
\text { follow-up }\end{array}$ & $\begin{array}{l}\text { Continued ASV } \\
\text { significantly lowered } \\
\text { all-cause mortality and } \\
\text { cardiac death rate }\end{array}$ \\
\hline $\begin{array}{l}\text { HeTLAND et al., } \\
2016 \text { [53] }\end{array}$ & $\begin{array}{l}\text { Retrospective } \\
\text { observational study } \\
\text { Østfold, Norway } \\
\text { 2007-2012 }\end{array}$ & $\begin{array}{l}\text { Heart failure NYHA class II- } \\
\text { IV, LVEF } \leqslant 45 \% \text {; CSR pattern } \\
\geqslant 25 \% \text { of sleeping time and } \\
\text { dominant central sleeping } \\
\text { pattern via polygraphy }\end{array}$ & $\begin{array}{c}75 \text { patients treated with ASV } \\
\text { ( } \mathrm{n}=31 \text { with ASV for }>3- \\
18 \text { months versus } \mathrm{n}=44 \\
\text { control) } \\
\text { (AutoSet-CS) }\end{array}$ & $\begin{array}{c}\text { Mortality and hospital admission of } \\
\text { any cause and number of days in } \\
\text { hospital in total }\end{array}$ & 18 months & $\begin{array}{l}\text { ASV did not significantly } \\
\text { affect CV death or } \\
\text { combined CV death or } \\
\text { hospital admissions after } \\
18 \text { months; trend toward } \\
\text { better CV event-free } \\
\text { survival for ASV usage }\end{array}$ \\
\hline $\begin{array}{l}\text { BoRDIER and } \\
\text { LATASTE, } 2019 \\
\text { [54] }\end{array}$ & $\begin{array}{l}\text { Retrospective study } \\
\text { 2006-2018 }\end{array}$ & $\begin{array}{l}\text { Patient from the sleep unit } \\
\text { of the CV department } \\
\text { treated with ASV for sleep } \\
\text { apnoea (C/M/O apnoeas via } \\
\text { PG) }\end{array}$ & $\begin{array}{l}32 \text { patients with ASV } \\
8 \text { deaths }\end{array}$ & CV mortality & Survival & $\begin{array}{c}\text { CV deaths not } \\
\text { predominant } \\
\text { No relationship between } \\
\text { sleep apnoea or ASV and } \\
\text { death }\end{array}$ \\
\hline $\begin{array}{l}\text { MANSUKHANI } \\
\text { et al., } 2019 \\
\text { [55] }\end{array}$ & $\begin{array}{l}\text { Population-based } \\
\text { study, using the } \\
\text { Rochester } \\
\text { Epidemiology } \\
\text { Project database }\end{array}$ & $\begin{array}{c}\text { CSA (AHI } 41.6 \\
\pm 26.5 \text { events } \cdot \mathrm{h}^{-1} \text { ), with ASV } \\
\text { therapy }(65 \% \geqslant 4 \mathrm{~h} \text { per night } \\
\text { on } \geqslant 70 \% \text { nights in their first } \\
\text { month), and had } \geqslant 1 \text { month } \\
\text { of clinical data before and } \\
\text { after ASV initiation }\end{array}$ & $\begin{array}{l}309 \text { CSA patients under ASV } \\
\text { versus healthcare utilisation }\end{array}$ & $\begin{array}{l}\text { Rates of hospitalisations, emergency } \\
\text { department visits, outpatient visits } \\
\text { and medications prescribed per year } \\
\text { (mean } \pm \text { SD) }\end{array}$ & $\begin{array}{l}2 \text { years pre- } \\
\text { and post-ASV } \\
\text { initiation }\end{array}$ & $\begin{array}{l}\text { ASV did not change } \\
\text { healthcare utilisation }\end{array}$ \\
\hline
\end{tabular}




\begin{tabular}{|c|c|c|c|c|c|c|}
\hline $\begin{array}{l}\text { Study/authors, } \\
\text { year } \\
\text { [reference] }\end{array}$ & Design & Population & Intervention & Primary outcome & $\begin{array}{l}\text { Median or } \\
\text { average } \\
\text { follow-up }\end{array}$ & Results \\
\hline $\begin{array}{l}\text { ADVENT-HF } \\
\text { trial, } \\
\text { recruiting } \\
\text { [56] }\end{array}$ & $\begin{array}{l}\text { Multicentre, } \\
\text { multinational, } \\
\text { randomised, } \\
\text { parallel-group, } \\
\text { open-label trial } \\
\text { Canada }\end{array}$ & $\begin{array}{l}\text { Chronic HFrEF }(\leqslant 45 \%) \text { and } \\
\text { SDB (OSA or CSA) with AHI } \\
\geqslant 15 \text { events } \cdot h^{-1} \text { via PSG }\end{array}$ & $\begin{array}{c}\text { Estimated } n>800 \text {, still } \\
\text { recruiting } 524 \text { patients ( } 31 \% \\
\text { CSA, 69\% OSA) randomised } \\
\text { until February } 2018 \text { on } \\
\text { medical therapy alone or } \\
\text { ASV (AutoSet-CS) with nasal } \\
\text { mask }\end{array}$ & $\begin{array}{l}\text { All-cause mortality, first } \\
\text { hospitalisation for CV diseases, } \\
\text { new-onset atrial fibrillation/flutter } \\
\text { requiring anticoagulation but not } \\
\text { hospitalisation or implantable } \\
\text { cardioverter-defibrillator shock not } \\
\text { requiring hospitalisation }\end{array}$ & $\begin{array}{l}\text { Every } \\
6 \text { months }\end{array}$ & Awaited \\
\hline
\end{tabular}

ASV studies with mortality as primary outcome. The table summarises the results of additional studies on ASV in heart failure and central sleep apnoea (CSA). Methodologies incompletely describe the types of masks and ASV devices used, sleep study, algorithm of titration and compliance to the device. Only one study (FACE) stratified patients in relation to the severity of heart failure with reduced ejection fraction (HFrEF). CHF: chronic heart failure; LVEF: left ventricular ejection fraction; HFmrEF: heart failure with mid-range ejection fraction; HFpEF: heart failure with preserved ejection fraction; SDB: sleep disordered breathing; OSA: obstructive sleep apnoea; AHI: apnoea-hypopnoea index; CV: cardiovascular; QoL: quality of life; NYHA: New York Heart Association; CSR: Cheyne-Stokes respiration. 
hypercapnic ventilatory response and it was worst in patients with both increased hypoxic and hypercapnic ventilatory response.

\section{Conclusion}

These findings indicate that there are substantial differences within the group of heart failure patients with periodic breathing in terms of outcome. It is not a homogenous population with unique prognosis. Characteristics of potential phenotypes include the burden of hypoxaemia, variations of oxygen desaturation, chemoresponsiveness, ventilatory instability during wakefulness and sleep and lung volumes.

It is obvious that this hypothesis requires better definition, discrimination and prospective evaluation. However, it seems reasonable to include these parameters in the design and interpretation of future and, if possible, in published studies, by sharing open data to better understand survival and efficacy, benefits and harms under treatment. Including these parameters in future clinical routines will provide an appropriate classification to identify the CHF subgroup the most likely to respond to PAP therapies or alternatives.

Conflict of interest: W. Randerath reports grants and personal fees from Heinen \& Löwenstein, ResMed, Philipps Respironics, Inspire, Genzyme, Boehringer Ingelheim, Berlin Chemie and Roche Pharma, and personal fees from Vanda, outside the submitted work. O. Deleanu has nothing to disclose. S. Schiza has nothing to disclose. J-L. Pépin reports grants and personal fees from ResMed, Philips, Agiradom, AstraZeneca and SEFAM, grants from Fisher and Paykel, Mutualia, Vitalaire and Air Liquide Foundation, and personal fees from JAZZ and ITAMAR, during the conduct of the study.

\section{References}

1 Ponikowski P, Voors AA, Anker SD, et al. 2016 ESC Guidelines for the diagnosis and treatment of acute and chronic heart failure: The Task Force for the diagnosis and treatment of acute and chronic heart failure of the European Society of Cardiology (ESC). Developed with the special contribution of the Heart Failure Association (HFA) of the ESC. Eur Heart J 2016; 37: 2129-2200.

2 Randerath W, Verbraecken J, Andreas S, et al. Definition, discrimination, diagnosis and treatment of central breathing disturbances during sleep. Eur Respir J 2017; 49: 1600959.

3 Arzt M, Woehrle H, Oldenburg O, et al. Prevalence and predictors of sleep-disordered breathing in patients with stable chronic heart failure: the SchlaHF registry. JACC Heart Fail 2016; 4: 116-125.

4 Arzt M, Oldenburg O, Graml A, et al. Phenotyping of sleep-disordered breathing in patients with chronic heart failure with reduced ejection fraction - the SchlaHF registry. J Am Heart Assoc 2017; 6: e005899.

5 Bitter T, Westerheide N, Prinz C, et al. Cheyne-Stokes respiration and obstructive sleep apnoea are independent risk factors for malignant ventricular arrhythmias requiring appropriate cardioverter-defibrillator therapies in patients with congestive heart failure. Eur Heart J 2011; 32: 61-74.

6 Khayat R, Jarjoura D, Porter K, et al. Sleep disordered breathing and post-discharge mortality in patients with acute heart failure. Eur Heart J 2015; 36: 1463-1469.

7 Eckert DJ, Jordan AS, Merchia P, et al. Central sleep apnea: pathophysiology and treatment. Chest 2007; 131: 595-607.

8 Baillieul S, Revol B, Jullian-Desayes I, et al. Diagnosis and management of central sleep apnea syndrome. Expert Rev Respir Med 2019; 13: 545-557.

9 Andreas S. Central sleep apnea and chronic heart failure. Sleep 2000; 23: Suppl. 4, S220-S223.

10 Arzt M, Harth M, Luchner A, et al. Enhanced ventilatory response to exercise in patients with chronic heart failure and central sleep apnea. Circulation 2003; 107: 1998-2003.

11 Jelic S, Le Jemtel TH. Sleep-disordered breathing in acute decompensated heart failure. Curr Heart Fail Rep 2009; 6: 169-175.

12 Mortara A, Sleight P, Pinna GD, et al. Association between hemodynamic impairment and Cheyne-Stokes respiration and periodic breathing in chronic stable congestive heart failure secondary to ischemic or idiopathic dilated cardiomyopathy. Am J Cardiol 1999; 84: 900-904.

13 Corrà $\mathrm{U}$, Pistono $\mathrm{M}$, Mezzani $\mathrm{A}$, et al. Sleep and exertional periodic breathing in chronic heart failure: prognostic importance and interdependence. Circulation 2006; 113: 44-50.

14 Brack T, Thüer I, Clarenbach CF, et al. Daytime Cheyne-Stokes respiration in ambulatory patients with severe congestive heart failure is associated with increased mortality. Chest 2007; 132: 1463-1471.

15 Kazimierczak A, Krzyzanowski K, Wierzbowski R, et al. Resolution of exercise oscillatory ventilation with adaptive servoventilation in patients with chronic heart failure and Cheyne-Stokes respiration: preliminary study. Kardiol Pol 2011; 69: 1266-1271.

16 Naughton MT. Cheyne-Stokes respiration: friend or foe? Thorax 2012; 67: 357-360.

17 Brack T, Jubran A, Laghi F, et al. Fluctuations in end-expiratory lung volume during Cheyne-Stokes respiration. Am J Respir Crit Care Med 2005; 171: 1408-1413.

18 Sands SA, Edwards BA, Kee K, et al. Loop gain as a means to predict a positive airway pressure suppression of Cheyne-Stokes respiration in patients with heart failure. Am J Respir Crit Care Med 2011; 184: 1067-1075.

19 Wexels JC, Mjøs OD. Effects of carbon dioxide and $\mathrm{pH}$ on myocardial function in dogs with acute left ventricular failure. Crit Care Med 1987; 15: 1116-1120.

20 Porter JM, Markos F, Snow HM, et al. Effects of respiratory and metabolic pH changes and hypoxia on ropivacaine-induced cardiotoxicity in dogs. Br J Anaesth 2000; 84: 92-94.

21 Levine M, Cleave JP, Dodds C. Can periodic breathing have advantages for oxygenation? J Theor Biol 1995; 172: 355-368.

22 Javed F, Mayhew AJ, Shea AK, et al. Association between hormone therapy and muscle mass in postmenopausal women: a systematic review and meta-analysis. JAMA Netw Open 2019; 2: e1910154. 
23 Walsh JT, Andrews R, Starling R, et al. Effects of captopril and oxygen on sleep apnoea in patients with mild to moderate congestive cardiac failure. Br Heart J 1995; 73: 237-241.

24 Tamura A, Kawano Y, Naono S, et al. Relationship between $\beta$-blocker treatment and the severity of central sleep apnea in chronic heart failure. Chest 2007; 131: 130-135.

25 Spaak J, Egri ZJ, Kubo T, et al. Muscle sympathetic nerve activity during wakefulness in heart failure patients with and without sleep apnea. Hypertension 2005; 46: 1327-1332.

26 Perger E, Jutant EM, Redolfi S. Targeting volume overload and overnight rostral fluid shift: a new perspective to treat sleep apnea. Sleep Med Rev 2018; 42: 160-170.

27 Skobel EC, Sinha AM, Norra C, et al. Effect of cardiac resynchronization therapy on sleep quality, quality of life, and symptomatic depression in patients with chronic heart failure and Cheyne-Stokes respiration. Sleep Breath 2005; 9: 159-166.

28 Bordier P, Orazio S, Hofmann P, et al. Short- and long-term effects of nocturnal oxygen therapy on sleep apnea in chronic heart failure. Sleep Breath 2015; 19: 159-168.

29 Bordier P, Lataste A, Hofmann P, et al. Nocturnal oxygen therapy in patients with chronic heart failure and sleep apnea: a systematic review. Sleep Med 2016; 17: 149-157.

30 Lorenzi-Filho G, Rankin F, Bies I, et al. Effects of inhaled carbon dioxide and oxygen on Cheyne-Stokes respiration in patients with heart failure. Am J Respir Crit Care Med 1999; 159: 1490-1498.

31 Xie A, Skatrud JB, Puleo DS, et al. Apnea-hypopnea threshold for $\mathrm{CO}_{2}$ in patients with congestive heart failure. Am J Respir Crit Care Med 2002; 165: 1245-1250.

32 Khayat RN, Xie A, Patel AK, et al. Cardiorespiratory effects of added dead space in patients with heart failure and central sleep apnea. Chest 2003; 123: 1551-1560.

33 Javaheri S, Parker TJ, Wexler L, et al. Effect of theophylline on sleep-disordered breathing in heart failure. $N$ Engl J Med 1996; 335: 562-567.

34 Ponikowski P, Javaheri S, Michalkiewicz D, et al. Transvenous phrenic nerve stimulation for the treatment of central sleep apnoea in heart failure. Eur Heart J 2012; 33: 889-894.

35 Randerath W, Herkenrath S. Unilateral phrenic nerve stimulation in the therapeutical algorithm of central sleep apnoea in heart failure. Curr Opin Pulm Med 2019. In press https://doi.org/10.1097/MCP.0000000000000606.

36 Bradley TD, Logan AG, Kimoff RJ, et al. Continuous positive airway pressure for central sleep apnea and heart failure. N Engl J Med 2005; 353: 2025-2033.

37 Dellweg D, Kerl J, Hoehn E, et al. Randomized controlled trial of noninvasive positive pressure ventilation (NPPV) versus servoventilation in patients with CPAP-induced central sleep apnea (complex sleep apnea). Sleep 2013; 36: 1163-1171

38 Javaheri S, Brown LK, Randerath WJ. Positive airway pressure therapy with adaptive servoventilation: part 1: operational algorithms. Chest 2014; 146: 514-523.

39 Randerath WJ, Nothofer G, Priegnitz C, et al. Long-term auto-servoventilation or constant positive pressure in heart failure and coexisting central with obstructive sleep apnea. Chest 2012; 142: 440-447.

40 Oldenburg $\mathrm{O}$, Bitter $\mathrm{T}$, Lehmann $\mathrm{R}$, et al. Adaptive servoventilation improves cardiac function and respiratory stability. Clin Res Cardiol 2011; 100: 107-115.

41 Sharma BK, Bakker JP, McSharry DG, et al. Adaptive servoventilation for treatment of sleep-disordered breathing in heart failure: a systematic review and meta-analysis. Chest 2012; 142: 1211-1221.

42 Hetzenecker A, Escourrou P, Kuna ST, et al. Treatment of sleep apnea in chronic heart failure patients with auto-servo ventilation improves sleep fragmentation: a randomized controlled trial. Sleep Med 2016; 17: 25-31.

43 Toyama T, Hoshizaki H, Kasama S, et al. Adaptive servo-ventilation therapy improves cardiac sympathetic nerve activity, cardiac function, exercise capacity, and symptom in patients with chronic heart failure and Cheyne-Stokes respiration. J Nucl Cardiol 2017; 24: 1926-1937.

44 Takama N, Kurabayashi M. Effect of adaptive servo-ventilation on 1-year prognosis in heart failure patients. Circ J 2012; 76: 661-667.

45 Cowie MR, Woehrle $\mathrm{H}$, Wegscheider $\mathrm{K}$, et al. Adaptive servo-ventilation for central sleep apnea in systolic heart failure. N Engl J Med 2015; 373: 1095-1105.

46 Randerath W, Khayat R, Arzt M, et al. Missing links. Sleep Med 2015; 16: 1495-1496.

47 Eulenburg $\mathrm{C}$, Wegscheider $\mathrm{K}$, Woehrle $\mathrm{H}$, et al. Mechanisms underlying increased mortality risk in patients with heart failure and reduced ejection fraction randomly assigned to adaptive servoventilation in the SERVE-HF study: results of a secondary multistate modelling analysis. Lancet Respir Med 2016; 4: 873-881.

48 Javaheri S, Brown L, Randerath W, et al. SERVE-HF: more questions than answers. Chest 2016; 149: 900-904.

49 Knitter J, Bailey OF, Poongkunran C, et al. Comparison of physiological performance of four adaptive servo ventilation devices in patients with complex sleep apnea. Am J Respir Crit Care Med 2019; 199: 925-928.

50 d'Ortho M-P, Tamisier R, Levy P, et al. FACE: A prospective multicentre observational cohort study in patients with chronic heart failure (CHF) and central sleep apnoea (CSA) treated with adaptive servoventilation (ASV). Eur Respir J 2013; 42: Suppl. 57, P324.

51 O'Connor CM, Whellan DJ, Fiuzat M, et al. Cardiovascular outcomes with minute ventilation-targeted adaptive servo-ventilation therapy in heart failure: the CAT-HF trial. J Am Coll Cardiol 2017; 69: 1577-1587.

52 Imamura $\mathrm{T}$, Kinugawa $\mathrm{K}$, Nitta $\mathrm{D}$, et al. Long-term adaptive servo-ventilator treatment prevents cardiac death and improves clinical outcome. Int Heart J 2016; 57: 47-52.

53 Hetland A, Haugaa KH, Vistnes M, et al. A retrospective analysis of cardiovascular outcomes in patients treated with ASV. Scand Cardiovasc J 2017; 51: 106-113.

54 Bordier P, Lataste A. Death in patients with adaptive servo-ventilation for sleep apnea and no specific SERVE-HF profile: a case series study. Respir Med Case Rep 2018; 26: 68-72.

55 Mansukhani MP, Kolla BP, Naessens JM, et al. Effects of adaptive servoventilation therapy for central sleep apnea on health care utilization and mortality: a population-based study. J Clin Sleep Med 2019; 15: 119-128.

56 Lyons OD, Floras JS, Logan AG, et al. Design of the effect of adaptive servo-ventilation on survival and cardiovascular hospital admissions in patients with heart failure and sleep apnoea: the ADVENT-HF trial. Eur J Heart Fail 2017; 19: 579-587.

57 Perger E, Lyons OD, Inami T, et al. Predictors of 1-year compliance with adaptive servoventilation in patients with heart failure and sleep disordered breathing: preliminary data from the ADVENT-HF trial. Eur Respir J 2019; 53: 1801626. 
58 Messineo L, Magri R, Corda L, et al. Phenotyping-based treatment improves obstructive sleep apnea symptoms and severity: a pilot study. Sleep Breath 2017; 21: 861-868.

59 Arzt M, Floras JS, Logan AG, et al. Suppression of central sleep apnea by continuous psitive airway pressure and transplant-free survival in heart failure: a post hoc analysis of the Canadian Continuous Positive Airway Pressure for Patients with Central Sleep Apnea and Heart Failure Trial (CANPAP). Circulation 2007; 115: 3173-3180.

60 Watanabe E, Kiyono K, Matsui S, et al. Prognostic importance of novel oxygen desaturation metrics in patients with heart failure and central sleep apnea. J Card Fail 2017; 23: 131-137.

61 Granitza P, Kraemer JF, Schoebel C, et al. Is dynamic desaturation better than a static index to quantify the mortality risk in heart failure patients with Cheyne-Stokes respiration? Chaos 2018; 28: 106312.

62 Perger E, Inami T, Lyons OD, et al. Distinct patterns of hyperpnea during Cheyne-Stokes respiration: implication for cardiac function in patients with heart failure. J Clin Sleep Med 2017; 13: 1235-1241.

63 Giannoni A, Emdin M, Bramanti F, et al. Combined increased chemosensitivity to hypoxia and hypercapnia as a prognosticator in heart failure. J Am Coll Cardiol 2009; 53: 1975-1980. 